La Casa Enferma: Sociología de la Enfermedad de Chagas. Roberto BriceñoLeón. Fondo Editorial Acta Cientifica de Venezuela y Consorcio de Ediciones Capriles C. A.: Caracas, Venezuela, 1990. 149 p., figuras, tabelas e bibliografia. (Brochura) ISBN 980-6201-08-6

O livro "La Casa Enferma: Sociología de la Enfermedad de Chagas", de Roberto BriceñoLeón, é o resultado de uma investigação científica sobre o Programa Nacional de Habitação Rural na Venezuela e o Controle de Doença de Chagas. Este programa, que foi iniciado em 1958 sob a direção do Dr. Arnaldo Gabaldon, teve por objetivo principal substituir as habitações rurais precárias e insalubres por outras adequadas que contribuíssem para a melhoria das condições de saúde.

La Casa Enferma: Sociología de la Enfermedad de Chagas é um trabalho que desenvolveu, de acordo com rigorosa metodologia científica, uma investigação sociológica em doença de Chagas com enfoque inovador, inteligente e crítico, superando o que já foi até então realizado sobre o assunto. É um trabalho objetivo, muito bem documentado, conciso, conclusivo e de agradável leitura. Seus resultados transcendem o tema específico, sendo importante modelo para ser levado em consideração pelos planejadores das políticas públicas de saúde, no que se refere aos temas de ações de controle e prevenção. O livro está estruturado em duas partes: 1' A Transmissão, e 2' O Controle.

A primeira parte, A Transmissão, compreende quatro capítulos: I. A Doença de Chagas; II. A Habitação Rural e a Doença de Chagas; III. O Estudo Sociológico da Transmissão Vetorial, e IV. O Indivíduo, suas Circunstâncias e a Doença. Foi estudada e discutida, no conjunto dos capitulos, a história natural e social da doença de Chagas, nos seus aspectos de distribuição geográfica, morbidade, prevalência, patologia, transmissão, migrações, ciclo silvestre $\mathrm{x}$ ciclo doméstico e as modificações ambientais, e a condição da habitação como abrigo dos vetores.

A segunda parte, $O$ Controle, compreende mais quatro capitulos, seqüenciais, a partir do IV anterior, que são: V. As Políticas de Con- trole da Doença e seus Efeitos Perversos. VI. Micromudanças Sociais: Abordagem Investigação-Ação. VII. O Controle Adequado da Doença; VIII. A Sociedade Sadia.

$A$ investigação de Briceño-León abordou o periodo de 1984-1988 e foi realizada de forma multidisciplinar, utilizando métodos de sociologia conjugados aos conhecimentos de biologia comportamental do vetor local - (Rhodnius prolixus), do Trypanosoma cruzi. Aplicou técnicas de investigação quantitativas, combinadas à pesquisa-ação, estudos históricos e análises contemporâneas nos contextos macro e micro-social, com abordagem antropológica. $O$ objetivo geral foi compreender a doença de Chagas nas suas dimensões individual e coletiva, no sentido de encontrar caminhos para o rompimento do ciclo de transmissão - vetor $x$ parasita $x$ hospedeiro humano - a partir de modificações do comportamento individual das pessoas, da organização e do meio ambiente.

Para explicar todo o processo que determinou a endemização da doença de Chagas na Venezuela, Briceño-León utilizou dois níveis de abordagens: a) Macrossocial, em que a sociedade é vista como um todo: "Os grandes processos sociais, históricos ou estruturais que permitem analisar o subdesenvolvimento, as formas de produção da sociedade, sua cultura, e a ideologia da colonização"; b) Microssocial neste é relevado o papel exercido pelo indivíduo na sociedade, seu comportamento, suas atitudes e responsabilidades, percepção e conhecimentos. Duas teorias básicas foram empregadas: a) de corte situacional, procura explicar as condições objetivas que determinam a existência do tipo de habitação e a transmissão, traduzidas pela pobreza do trabalhador rural, resultante do nível de exploração a que está submetido; b) de natureza cultural e psicossocial - procura explicar as condições internas dos indivíduos, traduzidas pelo seu nível educacional, valores, normas, cultura etc.

A hipótese geral do trabalho foi a de que o status da habitação, a relação do trabalhador com a terra, o focus de controle, as crenças sobre a doença e o sentimento de enraizamento determinam a existência ou não das condições da habitação para a colonização do vetor do 
Trypanosoma cruzi. Assim, as condições da habitação estão relacionadas a condições de caráter objetivo e subjetivo. As diferenças são consideradas diante das expectativas que $o$ indivíduo tem do controle, que dependem do indivíduo ele mesmo e suas circunstâncias: presente, passado, natureza da cultura, da fantasia, da interpretação imaginária e a relação com o mundo real.

Analisando a prevalência da doença de Chagas na América Latina, em áreas rurais e urbanas, Briceño-León discute os fatores políti$\cos$, sociais e econômicos dominantes nessas regiões. $\mathrm{Na}$ Venezuela, particularmente nas áreas rurais, o autor declina as formas $\mathrm{e}$ as relações de produção que determinam a situação fundiária, as habitações precárias que favorecem condiçōes ideais para o abrigo do vetor, qualidade de vida, analfabetismo, comportamento social individual e coletivo. Destaca o papel dos movimentos migratórios das populações rurais na distribuição e aumento de transmissão, considerando a invasão do vetor a novos sítios habitacionais por destruição do ambiente natural e pelo transporte passivo. Analisando as medidas de controle que foram conduzidas no país, o autor faz dois cortes na história em relação às políticas de saúde: 1) Antes dos anos 60 - os planos foram pensados no contexto de mudanças da sociedade; 2 ) Anos 60 - o fazer algo pela Saúde foi marcado por um pensamento e tipos de ação, sem considerar os princípios de comportamento social, isto é, ações individuais, clientelistas e isoladas, com efeitos perversos no sentido sociológico. Foram abandonadas as práticas alternativas, construídas a partir de valores próprios da comunidade, em nome de uma pretensa modernidade, determinada pelos altos ingressos do petróleo. Assim, em relação ao controle de doença de Chagas, o programa de construção e melhoria das habitações rurais Terra+Cimento foi substituído pelo Cimento+Ferro, diminuindo a participação da população e incrementando o clientelismo representado através de doações. Por outro lado, mostrou que o modelo de educação sanitária no programa veiculou apenas informações teóricas $\mathrm{x}$ comportamento, ignorando os saberes prévios e, portanto, de eficácia muito limitada. Discutiu, ainda, as pretensas propostas e tentativas de construção em mutirão, qualificando-as como experiências negativas, onde presunçosamente se assumiu que as pessoas, a nivel popular, têm um comportamento coletivo distinto, enfatizando o erro que se cometeu ao se estabelecer programas que subestimam as diferenças individuais. Considerou a importância de ser valorizado o esforço individual, ensinando a lutar por uma sociedade melhor. Nesse contexto, demonstrou na sua investigação as imensas possibilidades que a população tem de responder ante a situações novas de mudança social $e$ ante a circunstâncias que reclamam o esforço e o trabalho, desde que as intervenções incrementem a responsabilidade individual, confiança, participação voluntária consciente, estimulando a resolução de seus próprios problemas, e valorizem o trabalho e não as doações.

Briceño-León conclui, através do modelo utilizado nesta investigação, que a doença de Chagas existe como processo biológico real em milhões de pessoas, mas não como feito cultural. Para seu controle, é importante a população criar uma cultura da doença de Chagas, isto é, converter o problema da doença como conhecido e reconhecido pelos indivíduos, sendo estes capazes de realizar atividades que os levem a proteger-se da transmissão. Nesse sentido, ressalta que é fundamental contar diretamente com a população em risco, pois são os primeiros atores do processo doença. Desenvolver a cultura do controle da doença significa incrementar a autoconfiança da população, e para isto é necessário que esta possa controlar os recursos, manejar, manipular a tecnologia e fazer o seu próprio destino como pessoa e familia, mas existindo também como grupo social e coletivo. As ações de controle devem estar, em conseqüência, adequadas à situação dos indivíduos, aos níveis de vida que têm as familias, às formas de organização social e à cultura, e ser desenhadas de forma tal que fomentem a compreensão da doença e sua conformação como parte da cultura global. Devem também contar com saberes e técnicas populares que, confrontados aos saberes e 
técnicas formais, encontrem alternativas apropriadas, combinando os esforços da população com aqueles do estado.

Considerando que "a saúde é um tema que está completamente integrado à situação global da sociedade, sua permanência, transitoriedade ou fragilidade dependem da maneira como a sociedade está estruturada, das práticas de vida cotidiana, da maneira como organiza a produção, das formas como distribuem a riqueza, dos vínculos que estabelecem com a natureza e das formas que concebem para o controle da doença". Nesse contexto, a doença de Chagas existe porque existe a pobreza do trabalhador rural latino-americano, porque suas habitações estão construídas de uma maneira precária, porque o fruto de seu trabalho apenas dá para sobreviver, porque a história de fracasso o fez ter pouca confiança em si mesmo, porque não houve acesso à evolução para superar-se como pessoa e como povo. Não ter doença de Chagas é fundamentalmente ter uma habitação decente, trabalho que proporcione condições suficientes para manter-se, cuidar da casa e mais alguma coisa, como educação e confiança dos indivíduos em si mesmos, em seu trabalho, suas ações e sua capacidade de organização.

Dalva A. Mello

Laboratório de Parasitologia PTLFS, Universidade de Brasilia

\section{Os Homossexuais e a Aids: Sociologia de} uma Epidemia. Michael Pollak. Estação Liberdade: São Paulo, Brasil, 1990. 212 p., gráficos, tabelas e bibliografia.

$C R \$ 25.000,00$

A obra de Pollack coloca especificamente a luta homossexual frente à AIDS, pensando a ação institucional de controle e prevenção, os conflitos pessoais e coletivos de identidade e comportamento e a disputa ideológica pertinente à epidemia de AIDS na França.

A análise encaminha o tema da gestão do risco e homossexualidade face às liberdades civis e responsabilidades individuais. Também discute a questão da passagem de informação ao público e a tensão gerada, decomente do confronto de interesses diversos.

$\mathrm{Na}$ primeira parte (capítulos 1, 2 e 3) estão os resultados de pesquisas anuais realizadas na França junto a leitores da revista homossexual Gai Pied Hebdo nos verões de 1985, 1986 e 1987, de caráter qualitativo, através de relatos biográficos sobre trajetórias individuais na tentativa de reconstruir a lógica do universo homossexual e sua dinâmica. Outros trezentos homossexuais foram utilizados como controles, com caracteristicas semelhantes à população masculina francesa quanto a indicadores de saúde e sócio-culturais; outros controles foram aidéticos, soropositivos e pessoas com sinais clínicos ou não, seus amigos, pais, amantes e médicos.

As entrevistas enfatizaram a AIDS em relação à homossexualidade e identidade. Os resultados apontaram para a implicação de status sorológico como importante na definição da vida pessoal e crise de identidade para os mais atingidos.

$\mathrm{Na}$ segunda parte (capítulos 4, 5 e 6) está o espectro da marginalização, estigmatização e preconceitos, juntamente com as disputas ideológicas perpassadas de concreções imaginárias milenares, com origens nas grandes epidemias históricas: são os esquemas culturais da punição do desviante social, da crítica da conduta pessoal e do comportamento sexual, que na homossexualidade sofre o agravo da diferenciação sócio-sexual.

Nesse contexto das forças sociais em conflito surge o amplo debate em torno de medidas e controle de prevenção da AIDS e defesa dos direitos de doentes e soropositivos e os efeitos na vida cotidiana.

O capítulo 1 aborda homossexualidade e identificação nas relações complexas que envolvem AIDS, ruptura familiar, comportamento sexual, exclusão da vida social normal e autocrítica na gestão do risco.

$A$ análise situa identificação em função de origem social, vínculos de classe e residência, em relação à idade, profissão e instrução, o que 